\title{
Sentidos de legitimação do ensino bilíngue português-inglês: efeitos do discurso institucional 1
}

Laura Fortes ${ }^{2}$

Resumo: Nossa pesquisa de doutorado propôs um estudo discursivo de sentidos de bilinguismo, educação bilíngue e currículo em escolas bilíngues português-inglês. Teoricamente orientada pela análise de discurso pecheutiana, a pesquisa analisou discursividades produzidas em torno do real da expansão dessas escolas, frequentemente justificada por uma demanda crescente pela aquisição da língua inglesa cada vez mais cedo. Neste artigo, apresentamos um recorte de nosso corpus, a saber, o discurso institucional, bem como suas incidências no discurso profissional. Nessas condições de produção, dois elementos constituem a base desse processo discursivo: a representação da instituição sem falhas e seu atravessamento pelas discursividades da mídia e do mercado.

Palavras-chave: Ensino Bilíngue. Discurso Institucional. Mídia. Mercado.

Abstract: This paper presents a discursive analysis carried out in my doctoral research, which proposed a study of bilingualism, bilingual education and curriculum in Brazilian PortugueseEnglish bilingual schools. Drawing on the materialist discourse analysis framework by Michel Pêcheux, it examined discursivities shaping the real of the fast increasing number of those schools, often justified by a growing demand for the acquisition of English at an earlier age. Research data comprised texts from institutional discourse and professional discourse. Under such conditions of production, I conclude that two elements play a crucial role in that discursive process: the representation of a flawless institution and its relations with media and market discourses.

Keywords: Bilingual Education. Institutional Discourse. Media. Market.

Resumen: Nuestra investigación doctoral propuso un estudio discursivo de sentidos de bilingüismo, educación bilingüe y currículo en las escuelas bilingües portugués-inglés. Teóricamente orientada por el análisis de discurso de Michel Pêcheux, la investigación analizó

\footnotetext{
1 Texto apresentado no Simpósio $O$ político-ideológico no ensino de língua(s), sob a coordenação de Claudia Pfeiffer e Marisa Grigoletto, no VIII SEAD - Seminário de Estudos em Análise do Discurso, realizado na Universidade Federal de Pernambuco (UFPE), no período de 12 a 15 de setembro de 2017. Uma versão ampliada deste texto foi publicada na Revista Eletrônica de Estudos Integrados em Discurso e Argumentação (cf.: FORTES, 2017) e baseia-se em uma análise apresentada em um dos capítulos de minha tese de doutorado (cf.: FORTES, 2016), com apoio da FAPESP (Processo no 2012/21924-3) e da CAPES (Processo no 3760/14-6).

2 Professora da Universidade Federal da Integração Latino-Americana (UNILA). Doutora em Letras pela USP, com realização de estágio sanduíche na UTS (University of Technology, Sydney). Membro dos Grupos de Pesquisa LEDI (Língua Estrangeira, Discurso e Identidade-USP) e Linguagem, Política e Cidadania (UNILA).
} 
discursividades producidas en torno al real de la expansión de esas escuelas, a menudo justificada por una demanda creciente por la adquisición de la lengua inglesa cada vez más temprano. En este artículo, presentamos un recorte de nuestro corpus, a saber, el discurso institucional, así como sus incidencias en el discurso profesional. En estas condiciones de producción, dos elementos constituyen la base de ese proceso discursivo: la representación de la institución sin fallas y su atravesamiento por las discursividades de los medios y del mercado.

Palabras clave: Enseñanza Bilingüe. Discurso Institucional. Medios. Mercado.

\section{Introdução}

O mito de Pigmaleão, apresentado pelo poeta latino Ovídio no ano VIII d.C., conta a história desse escultor cipriota que se apaixona pela estátua que ele próprio havia esculpido3 . Era tão profundo seu encantamento pelo objeto criado que ele passou a viver com ela, vestindo-a, beijando-a, acariciando-a, enfim, tirando-a do lugar de simulacro à qual estava condenada pela representação escultural materializada no gelado e inerte marfim. Por meio de seu desejo, o gesto de construção do simulacro desloca-se de um artefato inanimado e ausente para uma mulher idealizada e presentificada com quem ele passa a conviver, imaginariamente, mas sem deixar, entretanto, de adorná-la, exaltá-la, admirá-la, venerá-la. Não foi pela mulher que Pigmaleão apaixonou-se, mas pelo seu simulacro - projeção de seu próprio desejo nesse jogo de ausência/presença da imagem materializada da mulher, representação tão tangível em seu imaginário.

Da mesma forma que Pigmaleão apaixonou-se por seu próprio trabalho, Henry Higgins, o professor de fonética da peça Pygmalion, de George Bernard Shaw, realiza um trabalho semelhante ao de um escultor, "lapidando" a fala de Eliza Doolittle, buscando "desvencilhá-la" de seu inglês cockney e levá-la à "perfeição" do inglês dito "padrão", que identificava as classes mais favorecidas ${ }^{4}$. Enquanto o Pigmaleão

\footnotetext{
${ }^{3} \mathrm{~A}$ inspiração para a referência ao mito de Pigmaleão em nosso estudo nasceu durante uma fala do Prof. Eduardo Vieira da Cunha (UFRGS) na mesa-redonda Criação e Produção no Processo Artístico coordenada pela Profa. Raquel Moreira (FURG) em 16 de outubro de 2013 no VI SEAD (Seminário de Estudos em Análise do Discurso) na Universidade Federal do Rio Grande do Sul, Porto Alegre, RS. Também participaram dessa mesa-redonda a Profa. Freda Indursky (UFRGS) e o Prof. Carlos Gerbase (PUC-RS).

${ }^{4}$ The hardest job I ever tackled: make no mistake about that, mother. But you have no idea how frightfully interesting it is to take a human being and change her into a quite different human being by
} 
mitológico teve seu desejo realizado pelos deuses, que, comiserados, transformaram a sua estátua em mulher de carne e osso (Galatéia), o Professor Higgins viu a florista transformar-se na duquesa que ele tanto almejara. Mas ambos construíram objetos que foram fruto de sua idealização, projeção, objetos que representavam seu desejo, e que, portanto, não coincidiam com o desejo5 ${ }^{5}$.

Trazendo para o discurso o ponto fundamental de nosso argumento pela referência aos Pygmalions, poderíamos dizer que ambos os personagens constroem não apenas os seus objetos, mas uma relação imaginária com aquilo que o objeto lhes apresenta como tangível - não com a totalidade do objeto, que é impossível, uma vez que se faz presente apenas via representação ${ }^{6}$. Diríamos que a vida dos simulacros criados por Pigmaleão e Higgins constitui uma ilusão à qual eles se identificam para fazer sentido, o que implica necessariamente uma interpelação - trabalho da ideologia, pois, como nos ensina Althusser ([1969] 2007, p. 85): “a ideologia representa a relação imaginária dos indivíduos com suas condições reais de existência”, ou seja, a ideologia é concebida como “ilusão/alusão" (ALTHUSSER [1969] 2007, p. 86). Assim, é a representação dessa relação imaginária que produz o sujeito, i.e., a evidência de sua unidade imaginária, ao mesmo tempo em que produz a evidência da transparência do sentido no processo que Pêcheux ([1975] 1988a) denominou "interpelaçãoidentificação", fazendo referência explícita à concepção psicanalítica de sujeito trazida por Lacan, ao aproximá-la da teorização althusseriana de ideologia. Nessa aproximação teórica, Pêcheux propõe que, pelo trabalho do inconsciente, o sujeito esquece ${ }^{7}$ esse exterior que o determina, esquecimento que significa "o acobertamento da causa do sujeito no próprio interior de seu efeito" (PÊCHEUX [1975] 1988a, p. 183, nota 32), sendo esta a condição de seu assujeitamento ideológico e de sua identificação às determinações do interdiscurso. Assim, como nos lembra Pêcheux em seu "início de

creating a new speech for her. It's filling up the deepest gulf that separates class from class and soul from soul. (SHAW, [1912] 1953, p. 271).

5 Tal como nos lembra Shaw ([1912] 1953, p. 320) na última frase de Pygmalion: "Galatea never does quite like Pygmalion: his relation to her is too godlike to be altogether agreeable."

${ }^{6}$ Lembramos que nossa referência aqui é meramente ilustrativa e não desenvolve suficientemente 0 tema da representação, tão magistralmente abordado por Michel Foucault ([1966] 1999; [1973] 1988). ${ }^{7}$ Não é deliberadamente que o sujeito esquece, mas pelo trabalho do inconsciente. Segundo Lacan ([1971] 2009, p. 42), "[o] inconsciente não quer dizer nada, se não quiser dizer que, diga eu o que disser e onde quer que me posicione, mesmo que me posicione bem, eu não sei o que digo; e nenhum dos discursos, tais como os defini no ano passado, dá esperança, permite a alguém pretender, até esperar, de algum modo, saber o que diz". 
uma retificação" ao final de Semântica e discurso, tal determinação não é plena e o assujeitamento ideológico não se realiza sem a possibilidade de falhas, pois há, também, o trabalho do "inconsciente, isto é, a causa que determina o sujeito exatamente onde o efeito de interpelação o captura" (PÊCHEUX [1978] 1988b, p. 30o), produzindo, imaginariamente, a sua unidade e a univocidade do sentido.

A relação dos Pygmalions com seus respectivos simulacros é, portanto, imaginária, pois somente a partir da representação dessa relação que os sujeitos podem ser constituídos. Nessa relação imaginária, a coincidência entre o desejo e o objeto torna-se possível, produz sentidos para o sujeito por meio de sua identificação com sua própria projeção - efeito de "literalidade", onde o sujeito é capturado no processo de interpelação. É no imaginário que a causa e o efeito do sujeito se realizam: causa e efeito de sua própria existência, que lhe é apresentada como transparente e originada em seu interior. As falhas desse processo de interpelação-identificação não são percebidas/assimiladas pelos sujeitos, mas são apresentadas ao leitor nas constantes incertezas do jogo presença/ausência produzido pelas imagens - construídas imaginariamente - de seus objetos de adoração.

A alusão aos Pygmalions na designação de uma das categorias de análise de nosso corpus de pesquisa busca uma articulação entre a reflexão teórica que acabamos de apresentar e a análise das incidências do discurso institucional sobre o discurso profissional ${ }^{8}$. Nesse processo, priorizou-se a dimensão das representações imaginárias - que, como veremos, estão construídas em torno de sentidos de legitimação de um "ideal": práticas de ensino "ideais", alunos "ideais", sentidos construídos pela exterioridade do interdiscurso e que retornam ao discurso do sujeito como se fossem "seu" discurso pelo processo de interpelação-identificação. Assim, neste texto, nossa leitura do arquivo do discurso profissional focaliza seu atravessamento pelo discurso institucional em dois movimentos de interpretação: 1) como um processo discursivo especialmente marcado pela representação da instituição escolar bilíngue como uma instituição sem falhas; 2) como um processo discursivo fortemente sustentado por discursividades da mídia e do mercado.

8 Em nosso contexto de pesquisa (FORTES, 2016), o arquivo que denominamos "discurso profissional" foi composto por entrevistas semiestruturadas realizadas com professores e coordenadores atuando em três escolas bilíngues português-inglês na cidade de São Paulo. 


\section{Venerando a criação: efeitos de legitimação de uma instituição sem falhas}

Efeitos de sentido de legitimação perpassam as discursividades sobre o ensino bilíngue português-inglês em diversos campos, especialmente em textualidades da mídia, da academia e da divulgação institucional (FORTES, 2016) - efeito de legitimação que parece afetar similarmente os dizeres do discurso profissional, como veremos adiante. Para analisar esse processo discursivo, será importante que tenhamos em mente a reivindicação de Fuchs e Pêcheux ([1975] 1997, p. 171) por "uma teoria nãosubjetiva da constituição do sujeito em sua situação concreta de enunciador". Isso significa considerar o sujeito como efeito e não como fonte de sentido, uma vez que "fala considerando-se autor de seu discurso, desde uma posição imaginária." (BRAUNSTEIN, [1980] 2008, p. 76, tradução nossa9). Tal posição imaginária a partir da qual o sujeito enuncia produz a ilusão de que é origem de seu dizer e a ilusão de que é uno, centrado, expressando-se por uma “protonoção de 'eu” (SAAL; BRAUNSTEIN, [1980] 2008, p.110, tradução nossa ${ }^{10}$ ), que constitui a representação de uma unidade imaginária, efeito do trabalho da interpelação ideológica: "os indivíduos são sempre/já sujeitos" (ALTHUSSER, [1969] 2007, p. 98). Tal representação de “individualidade” constitui-se, assim, pelo processo de interpelação ideológica, que produz a ilusão da unidade do "eu", apagando sua exterioridade histórica. Mas, como nos ensina Pêcheux, o efeito-sujeito não se produz apenas pela interpelação ideológica, mas também pelo processo de “identificação imaginária que diz respeito à 'gênese do ego', ao ajustamento sempre inacabado do sujeito consigo mesmo" (PÊCHEUX, [1975] 1988a, p. 265). A evidência do sujeito como um "eu" uno e centrado produz-se ao mesmo tempo em que ele é capturado pela evidência de sentido transparente e unívoco ao identificarse com certa formação discursiva - exterioridade necessariamente "esquecida" pelo sujeito ${ }^{11}$.

\footnotetext{
9 Texto original: "[...] habla considerándose autor de su discurso, desde una posición imaginaria." (BRAUNSTEIN, [1980] 2008, p.76).

10 Texto original: "protonoción de 'yo"' (SAAL; BRAUNSTEIN, [1980] 2008, p. 110).

11 Tal processo se dá pela dupla interpelação do sujeito pela ideologia e pelo inconsciente, pois "[o] sujeito é sempre, e ao mesmo tempo, sujeito da ideologia e sujeito do desejo inconsciente e isso tem
} 
A partir do recorte do arquivo do discurso profissional aqui proposto, identificamos um efeito de legitimação da escola bilíngue produzido pelos dizeres de sujeitos-professores e de sujeitos-coordenadores, nos quais o "eu" que emerge na materialidade linguística configura-se a partir de fortes marcas de um lugar institucional incidindo sobre o dizer do sujeito. Na sequência discursiva 1 a seguir ${ }^{12}$, temos a interpelação-identificação do sujeito com a representação de sua individualidade enquanto enunciador por meio da materialidade linguística dos indicadores de 1 a pessoa “eu” e "a gente”, como destacamos:

1_SC_2_A: [...] eu me sinto muito responsável... por esse carimbo de bilíngue né? eu tenho que/ eu tenho que... entregar esse serviço bem feito... então eu me sinto muito responsável e/ eu estou sempre buscando essa/ essa qualidade esse controle dessa qualidade porque eu sei que eu não posso chamar de bilíngue e não estar né? dando esse serviço que a gente está vendendo aqui né?

Entretanto, o deslizamento da referência do "eu” para "a gente" constitui um equívoco que deixa escapar a não coincidência do dizer com o sujeito da enunciação (“eu”), que permanece identificado com a sua representação de individualidade, um efeito para o sujeito. Esse equívoco funciona pela inconsistência da referência e deixa entrever o lugar de constituição desses sentidos de ensino vinculados a um "serviço" lugar que não se fixa no sujeito singular (“eu”), mas desliza para um lugar institucional de produção de sentidos materializado num movimento de pluralização desse sujeito no sintagma "a gente". As marcas de um "enunciador-individual” que se confundem com um lugar de enunciação institucional aparecem numa materialidade similar nas seguintes sequências discursivas:

2_SP_2_B: [...] aqui para mim o programa é/ é excelente

3_SP_2_B: [...] acho que ESTOU satisfeita em estar em um programa bilíngue porque $e u$ acho que ele realmente funciona

4_SC_2_C: [...] eu ainda acredito que a educação bilíngue na Escola C é uma educação bilíngue que tem um foco que me agrada bastante e que eu acredito muito e que eu compro muito

a ver com o fato de nossos corpos serem atravessados pela linguagem antes de qualquer cogitação" (HENRY [1977] 1992, p. 188-9).

12 A fim de manter a identidade dos participantes em sigilo, todos os nomes próprios foram trocados e as escolas foram designadas Escola A, Escola B e Escola C. Os seguintes códigos de referência foram usados para os sujeitos: P: pesquisadora; SP: sujeito-professor; SC: sujeito-coordenador; 1, 2: atuação de acordo com o nível de ensino: 1 para Anos Iniciais do Ensino Fundamental (EB I) e 2 para Anos Finais do Ensino Fundamental (EB II). 
5_SC_2_C: [...] eu gosto muito de trabalhar aqui... eu acredito MUITO no que a gente FAZ... e a gente::.:. é assim eu acho que... a BASE do trabalho da Escola C e eu sei que seu/ o seu foco É no bilinguismo... mas eu acho que para além do bilinguismo é como se constitui essa educação bilíngue... [...] a gente VIVE uma educação bilíngue... que eu nã::.::::/ até hoje eu não vi em lugar nenhum... tudo bem... a gente acredita que é uma BOA educação bilíngue não teria uma melhor do que as outras... mas a gente acredita no que a gente faz

6_SC_2_C: [...] tem MUITO pesquisador... trabalhando aqui... exatamente pra gente BUSCAR uma EXCELÊNCIA e uma retidão... nesse sonho da Maria que é a dona da escola... né? então assim ela nos CONVOCA a contribuir com esse sonho... com a realização desse sonho...

7_SC_2_C: [...] a escola é planejada dessa forma ela é SONHADA dessa forma então a escola É... um espaço um contexto... BILÍNGUE dentro de uma São Paulo... que não é tão bilíngue assim... né?... dentro de um país Brasil que não é nada bilíngue... então a gente realmente tem o nosso jardim secreto... Escola C... ((rindo)) que:: eh::: nos possibilita dentro dos nossos muros PROPORCIONAR esta/ este contexto

Embora as marcas linguísticas indiquem a $1^{\underline{\underline{a}}}$ pessoa como "enunciadorindividual", tal individualidade constitui apenas um efeito, como temos tentado demonstrar. As posições discursivas "professor" e "coordenador" aparecem recobertas pelo lugar de dizer do enunciador-individual "eu”, que, por sua vez, encontra-se atravessado pelo discurso institucional, identificado tanto pelas marcas linguísticas de exaltação da instituição como pelo deslizamento do indicador de $\mathbf{1}^{\underline{a}}$ pessoa do singular (“eu”) para o indicador de $1^{\text {a }}$ pessoa do plural (“a gente”).

Nesse processo discursivo, o sujeito encontra-se interpelado-identificado com uma representação imaginária da instituição como um lugar "sem falhas", materializada nos sintagmas/significantes "serviço bem feito", "controle dessa qualidade” (sequência 1), “o programa é excelente” (sequência 2), "ele [programa bilíngue] realmente funciona" (sequência 3), "educação bilíngue que tem um foco que me agrada bastante e que eu acredito muito e que eu compro muito" (sequência 4), "eu gosto muito de trabalhar aqui", "eu acredito muito no que a gente faz", "a gente vive uma educação bilíngue que [...] até hoje eu não vi em lugar nenhum”, "a gente acredita que é uma boa educação bilíngue”, "a gente acredita no que a gente faz" (sequência 5), "exatamente pra gente buscar uma excelência e uma retidão" (sequência 6), "a gente realmente tem o nosso jardim secreto... Escola C [...] que nos possibilita dentro dos nossos muros proporcionar [...] este contexto" (sequência 7). Especialmente na sequência 7, as metáforas do "jardim secreto" e do "sonho" são evocadas, mostrando um sujeito identificado com marcas de um dizer institucional que se produz na 
possibilidade de alcançar algo excepcional, utópico - a estátua de Pigmalião, a Eliza do professor Higgins... o "impossível" tornado "possível” na e por meio da instituição, que se constrói num lugar de realizações que não poderiam ser alcançáveis fora dela.

\section{Relações entre o discurso institucional e as discursividades da mídia e do mercado}

Em nossa pesquisa de doutorado (FORTES, 2016), concluímos que uma das discursividades mais proeminentes sobre as escolas bilíngues português-inglês aparece nas textualidades colocadas em circulação pela mídia jornalística, que, desde a década de 2000, vem dando destaque ao aumento do número desses estabelecimentos de ensino no "mercado", enfatizando as "vantagens" da educação bilíngue. O discurso da mídia parecia instaurar, assim, um dos espaços do "dizível" (ORLANDI, [1990] 2008; [1992] 2002a) sobre a educação bilíngue no Brasil, dando-lhe visibilidade a partir de determinados sentidos ${ }^{13}$.

A intensificação da circulação de informações sobre as escolas bilíngues na mídia constitui um movimento de regulação de sentidos não apenas sobre essa modalidade de ensino, mas também sobre as línguas em questão - o português e o inglês, no caso - e sobre os processos de aquisição de línguas evocados pelo significante "bilinguismo". Assim, certos sentidos (e não outros) são colocados em circulação pela mídia: sentidos de exaltação de uma "vantagem bilíngue", que produzem uma representação do bilinguismo e da educação bilíngue como saberes legitimados sobre (a relação entre o sujeito e) a língua, com marcas de discursividades do mercado ("nicho educacional disputado", "sonho de consumo") 14.

\footnotetext{
${ }^{13}$ Na matéria Cresce procura por escolas bilíngues no país, por exemplo, o "fenômeno" educacional do bilinguismo aparece assim enunciado: "O número de escolas bilíngues no Brasil saltou de $145 \mathrm{em}$ 2007 para 180 em 2009, registrando um aumento de 24\% no período. Neste ano, outros sete colégios estão abrindo as portas só em São Paulo. O surgimento de novas instituições revela um nicho educacional disputado, que se tornou sonho de consumo de famílias de classe média e alta." (AGÊNCIA ESTADO, 2010).

${ }^{14}$ As manchetes a seguir ilustram a circulação de sentidos dessa "vantagem bilíngue": Aprendizado precoce: Quanto mais cedo, mais fácil (Folha de São Paulo, 26/08/2003); Por um cérebro bilíngue (Revista Educação, 14/07/2011); Fluência em um segundo idioma e acesso ao estudo no exterior atraem brasileiros para escolas bilíngues (O Globo, 24/01/2008); Bebês têm aula de inglês antes
} 
Em um estudo discursivo sobre o ensino de inglês para crianças no Brasil, Garcia (2011) identificou o enunciado "quanto mais cedo, melhor" como predominante na produção de sentidos sobre o ensino da língua inglesa nesse contexto educacional. Tal enunciado perpassa esses dizeres, construindo a necessidade da aprendizagem precoce de inglês. Desse modo, nas textualidades da mídia, a escola bilíngue português-inglês é predominantemente significada como um lugar em que a demanda por esse tipo de aprendizagem seria contemplada plenamente, retroalimentando os sentidos da “vantagem bilíngue”, principalmente a partir da comparação com a modalidade de ensino de inglês em escolas regulares não-bilíngues.

Desse modo, no funcionamento do discurso da mídia sobre a educação bilíngue português-inglês, a instituição que oferece tal modalidade de ensino é significada como um lugar de "perfeição" a ser desejado (e consumido) por toda a sociedade (FORTES, 2016). Segundo Payer (2005), a mídia pode ser compreendida como o texto fundamental do mercado, o novo grande Sujeito da sociedade contemporânea, cujo "enunciado todo-poderoso [...], que funciona como lugar máximo de interpelação, pode ser resumido em uma palavra: 'sucesso'” (PAYER, 2005, p. 18). As sequências discursivas que trouxemos para análise mostram como os sujeitos são interpeladosidentificados por esse enunciado ao (se) significarem em relação à educação bilíngue, evocando frequentemente um lugar de legitimação da instituição na qual estão inseridos.

Em alguns momentos, foi possível identificar que o movimento de sentidos em torno desse lugar de legitimação ancora-se no modo de interpelação ideológica do mercado, numa racionalidade da educação como mercadoria e, portanto, passível de ser mensurada quanto a sua "qualidade” e "eficácia”. Um dos espaços do dizível sobre a educação bilíngue português-inglês encontra-se, assim, marcado por discursividades do mercado que colocam em circulação o significante "bilíngue" para funcionar metonimicamente como uma marca de legitimação do ensino, um lugar, portanto, desejado por muitas instituições escolares do setor privado. Assim, o efeito de legitimação das escolas bilíngues aparece relacionado à historicidade em funcionamento no processo metonímico de produção de sentidos sobre essas alfabetização (O Estado de São Paulo, 09/02/2012); Falar duas línguas desde cedo é positivo (O Estado de São Paulo, 23/09/2013). 
instituições. Retomemos a formulação 1, que analisamos na seção anterior e que ilustra como o sujeito (se) significa pela interpelação-identificação provocada pelo significante "bilíngue" num recorte do real marcado pela interseção com discursividades de mercado.

1_SC_2_A: [...] eu me sinto muito responsável... por esse carimbo de bilíngue né? eu tenho que/ eu tenho que... entregar esse serviço bem feito... então eu me sinto muito responsável e/ eu to sempre buscando essa/ essa qualidade esse controle dessa qualidade porque eu sei que eu não posso chamar de bilíngue e não estar né? dando esse serviço que a gente está vendendo aqui né?

A materialidade linguística que constitui o fio discursivo produz certos efeitos de sentido sobre a instituição escolar que a vinculam a um negócio cujo serviço oferecido/vendido é a modalidade de educação bilíngue. $O$ sujeito encontra-se capturado pelo efeito de evidência dessa representação, pelo trabalho da ideologia, assumindo a "responsabilidade" pela entrega do "serviço bem feito", pelo "controle de qualidade".

Ao analisar o espaço geográfico em sua relação com processos de urbanização, Milton Santos destaca a ampliação/renovação do setor terciário diante das condições da "economia internacional mundializada" (SANTOS, [1996] 2005, p. 79) e lista uma série de atividades primordiais para o seu funcionamento (marketing, engenharia, gerenciamento, etc), apontando a expansão do setor e das necessidades criadas por ele. O geógrafo brasileiro analisa a expansão do setor terciário na forma de novas atividades cujas necessidades são impostas pela globalização (ou, "economia internacional mundializada”, em suas palavras). Ora, se como o próprio autor afirma, tais necessidades são impostas “como se elas fossem naturais”, a operação de “imposição” não pode ser considerada senão pela via da ideologia em sua relação intrínseca com o campo do imaginário - pois, como já explicamos com Althusser ([1969] 2007, p. 85): “a ideologia representa a relação imaginária dos indivíduos com suas condições reais de existência”. Nessa perspectiva, as atividades do setor terciário constituem as condições reais de existência dos indivíduos, mas somente se tornam "necessárias" pela interpelação ideológica que produz a evidência dessa necessidade. E Santos ([1996] 2005, p. 80) nos deixa a pergunta instigante sobre o lugar da atividade educacional nessa reorganização do setor terciário: "Onde incluir a atividade 
educacional?" - pergunta que pode ser respondida a partir de uma leitura discursiva da formulação que estamos analisando.

Tal formulação se torna possível - “a condição do legível em relação ao próprio legível”, nos termos de Pêcheux ([1983] 1999, p. 52) - a partir do momento em que consideramos a exterioridade histórico-econômico-social tão bem teorizada pelo geógrafo brasileiro ao tratar dos processos de globalização e de urbanização no Brasil e no mundo. Assim, é "evidente" e "natural" que o sujeito enuncie que se sinta "responsável pelo carimbo de bilíngue" - como se fosse um "selo de garantia”, da mesma forma que a $\mathrm{OEBi}^{15}$ se coloca como uma organização que legitima o trabalho das instituições escolares bilíngues. Do mesmo modo, é possível enunciar que é preciso "entregar esse serviço bem feito", quando o "serviço" se enquadra ao que Milton Santos colocou em sua pergunta como "atividade educacional". E, enfim, falar em "qualidade" e "controle de qualidade" figura no eixo paradigmático de possibilidades de dizer sobre a educação e, mais especificamente, sobre a educação bilíngue. Parece ser pela via desse discurso $^{16}$ que o efeito de legitimação da instituição bilíngue se produz. Isso porque o campo da educação não está fora das novas configurações socioeconômicas trazidas pela globalização como "economia internacional mundializada" (SANTOS, [1996] 2005, p. 79) nos tempos neoliberais atuais. Não está fora, portanto, das injunções e das interpelações produzidas pelo mercado enquanto novo grande Sujeito.

\section{Considerações finais}

\footnotetext{
15 OEBi (Organização das Escolas Bilíngues do Estado de São Paulo), uma organização privada fundada em 2000 e cujo foco é oferecer suporte didático-pedagógico às escolas bilíngues que se associem à instituição.

${ }^{16}$ Alguns pesquisadores na área de educação têm analisado como a ideologia neoliberal tem inserido nos contextos educativos sentidos e práticas do mercado. Bueno (2003) dedica-se à análise do discurso da "qualidade total" na educação; Santos (2010) analisa o processo de mercantilização da educação superior brasileira privada; Garcia (2011) trata especificamente das modalidades de ensino de inglês para crianças pequenas no Brasil, concluindo que tal contexto educacional está alinhado ao discurso neoliberal. Buscamos nesses autores um diálogo para nossa análise dos efeitos de sentido de legitimação das instituições escolares bilíngues em seu atravessamento pelas discursividades de mercado (FORTES, 2016).
} 
Nossa leitura centralizou as discussões em torno do discurso institucional como um lugar de produção de um imaginário sobre a escola bilíngue cuja base significante predominante está na legitimação pela veneração de sua imagem. Daí a alusão ao personagem Pygmalion - tanto o de Ovídio, que admirava incessantemente a estátua esculpida por suas próprias mãos, quanto o de Shaw, que, encarnado na figura do professor Higgins, se gabava de ter transformado Eliza Doolittle em uma lady. Porque acreditaram demasiadamente em suas criações, os Pygmalions se viam atraídos cegamente por seus ideais de perfeição, que se tornaram parte de sua própria identidade. Similarmente, as representações imaginárias das instituições escolares bilíngues constituem o que formulamos como a construção discursiva da legitimação espaços de "perfeição" pelos quais os sujeitos são interpelados-identificados, afetando suas subjetividades na (im)possibilidade de alcançar seu desejo de completude.

A análise discursiva permitiu, num segundo movimento de interpretação, delinear a representação da instituição escolar bilíngue como uma "instituição sem falhas", funcionando a partir de sua sustentação em discursividades do mercado e da mídia, num processo de seleção, organização e circulação de sentidos que denominamos uma "metonímia de celebração da vantagem bilíngue” (FORTES, 2016). Os efeitos de sentido filiados a essas discursividades foram compreendidos a partir do processo histórico-econômico da inserção do campo da educação no setor terciário nas condições impostas pela "economia internacional mundializada" (SANTOS, [1996] 2005, p. 79) do neoliberalismo. Como vimos, essa inserção criou novas possibilidades de dizer sobre a educação, fazendo irromper significantes outrora restritos ao campo da economia/mercado, tais como "serviço" e "(controle de) qualidade", que passaram a fazer parte de um repertório de marcas linguísticas de exaltação/glorificação da instituição, produzindo representações da escola bilíngue como um "lugar sem falhas".

As breves considerações tecidas neste texto permitem-nos formular, finalmente, que o efeito de legitimação da instituição bilíngue funciona como um simulacro que vem ocupar o lugar de uma falta - uma falta que formulamos como uma "ausência de determinações regulamentadoras" acerca do funcionamento de escolas bilíngues português-inglês (FORTES, 2016). Tal ausência, especialmente circunscrita em torno de uma regulamentação curricular, foi apontada em algumas pesquisas (cf.: CORREDATO, 2010; FÁVARO, 2009; GARCIA, 2011; GIMENEZ, 2010, 2013; MOURA, 
2009, 2010 $)^{17}$, que mostram uma preocupação com a falta de produção de espaços de regulação específica - lacuna que pode impactar o trabalho do professor em diversas dimensões e também produzir seus efeitos na educação da sociedade brasileira em geral, uma vez que a falta de regulamentação acaba ampliando as possibilidades de oferta dessa modalidade de ensino pela iniciativa privada. Como consequência, tais modalidades de ensino transformam-se em novos "nichos de mercado" (GIMENEZ, 2010, p. 14), que são colocados em intensa circulação pelo discurso midiático, dando visibilidade e legitimação a representações de língua como "produto" e de ensino como “serviço”, tal como procuramos demonstrar nesta análise.

\section{Referências}

AGÊNCIA ESTADO. Cresce procura por escolas bilíngues no País. O Estado de São Paulo. 22/o1/2010. Disponível em: <http://www.estadao.com.br/noticias/geral,cresceprocura-por-escolas-bilingues-no-pais,499839,o.htm>. Acesso em: 22 abr. 2011.

ALTHUSSER, L. [1969] Aparelhos ideológicos de Estado: nota sobre os aparelhos ideológicos de Estado. Trad. Walter José Evangelista e Maria Laura Viveiros de Castro. 10.ed. Rio de Janeiro: Graal, 2007.

FORTES, Laura. Entre o silêncio e o dizível: Um estudo discursivo de sentidos de bilinguismo, educação bilíngue e currículo em escolas bilíngues português-inglês. Tese (Doutorado em Letras) - Departamento de Letras Modernas da Faculdade de Filosofia, Letras e Ciências Humanas. Universidade de São Paulo, São Paulo, 2016.

. Sentidos de legitimação do ensino bilíngue português-inglês: efeitos do discurso institucional. Revista Eletrônica de Estudos Integrados em Discurso e Argumentação, Ilhéus, n. 13, jan./jun., 2017.

BUENO, S. F. Pedagogia sem sujeito: qualidade total e neoliberalismo na educação. São Paulo: Annablume Editora, 2003.

\footnotetext{
17 Essas pesquisas, filiadas ao campo de estudos da LA, constituem gestos de interpretação daquilo
} que delineamos como espaços do silêncio do discurso político-educacional (FORTES, 2016). 
BRAUNSTEIN, N. Sujeto de la conciencia, sujeto del discurso, sujeto. In: BRAUNSTEIN, N. A. [1980] Psiquiatría, teoría del sujeto, psicoanálisis (hacia Lacan). Cd. de México: Siglo veintiuno Ed., 2008. p. 69-79.

CORREDATO, V. D. O Ensino Bilíngue em São Paulo: práticas de imersão em um contexto monolíngue. Monografia (Especialização). Anhanguera Educacional, 2010.

FÁVARO, F. M. A educação infantil bilíngue (português/inglês) na cidade de São Paulo e a formação dos profissionais da área: um estudo de caso. Dissertação (Mestrado). Pontifícia Universidade Católica de São Paulo. São Paulo, 2009.

FOUCAULT, M. [1966] As palavras e as coisas: uma arqueologia das ciências humanas. Trad. Salma Tannus Muchail. 8. ed. São Paulo: Martins Fontes, 1999.

FOUCAULT, M. [1973] Isto não é um cachimbo. Tradução de Jorge Coli. Rio de Janeiro: Paz e Terra, 1998.

FUCHS, C; PÊCHEUX, M. [1975]. A propósito da Análise Automática do Discurso: Atualização e Perspectivas. Trad. Péricles Cunha. In: GADET, F.; HAK, T. (orgs.) Por uma Análise Automática do Discurso: uma Introdução à obra de Michel Pêcheux. Tradutores: Bethania S. Mariani... [et al.]. 3. Ed. Campinas: Editora da UNICAMP, 1997. GARCIA, B. Quanto mais cedo melhor (?): uma análise discursiva do ensino de inglês para crianças. 2011. 216 p. Dissertação (Mestrado) - Faculdade de Filosofia, Letras e Ciências Humanas da Universidade de São Paulo, 2011.

GIMENEZ, T. Apresentação. In: ROCHA, C. H., TONELLI, J. R. A.; SILVA, K. A. da (Orgs). Língua estrangeira para crianças: ensino-aprendizagem e formação docente. Campinas, Pontes, 2010. p. 13-25.

GIMENEZ, T. A ausência de políticas para o ensino da língua inglesa nos anos iniciais de escolarização no Brasil. In: Nicolaides, C.; SILVA, K. A. da; TÍLIO, R.; ROCHA, C. H. (Org.). Política e Políticas Linguísticas. Campinas: Pontes Editores, 2013, p. 199-218.

HENRY, P. A ferramenta imperfeita: Língua, sujeito e discurso. Trad. Maria Fausta P. de Castro. Campinas: Editora da Unicamp, 1992.

LACAN, J. Seminário, livro 18: de um discurso que não fosse semblante (1971). Trad. Vera Ribeiro. Rio de Janeiro: Jorge Zahar Ed., 2009.

MOURA, S. de A. Com quantas línguas se faz um país? Concepções e práticas de ensino em uma sala de aula na educação bilíngue. Dissertação de Mestrado, Faculdade de Educação da Universidade de São Paulo. São Paulo, 2009. 
MOURA, S. de A. Educação bilíngue e currículo: de uma coleção de conteúdos a uma integração de conhecimentos. In: ROCHA, C. H., TONELLI, J. R. A.; SILVA, K. A. da (Orgs). Língua estrangeira para crianças: ensino-aprendizagem e formação docente. Campinas, Pontes, 2010, p. 269-295.

ORLANDI, E. P. [1992] As formas do silêncio: no movimento dos sentidos. 5 ed. Campinas, SP. Editora da Unicamp, 2002.

ORLANDI, E. P. [1990] Silêncio e sentido. In: .Terra à vista: discurso do confronto: velho e novo mundo. 2. ed. Campinas, SP: Editora da Unicamp, 2008. p. 5761.

PAYER, M. O. Linguagem e sociedade contemporânea: sujeito, mídia, mercado. Revista Rua. Núcleo de Desenvolvimento da Criatividade da Unicamp, n. 11, p. 9-25, mar. 2005. PÊCHEUX, Michel. [1975] Semântica e discurso: uma crítica à afirmação do óbvio. Trad. Eni Pulcinelli Orlandi, Lourenço Chacon Jurado Filho, Manoel Luiz Gonçalves Corrêa, Silvana Mabel Serrani. Campinas: Editora da UNICAMP, 1988a.

PÊCHEUX, M. [1978] Só há causa daquilo que falha ou o inverno político francês: início de uma retificação. In: PÊCHEUX, M. [1975] Semântica e discurso: uma crítica à afirmação do óbvio. Trad. Eni Pulcinelli Orlandi, Lourenço Chacon Jurado Filho, Manoel Luiz Gonçalves Corrêa, Silvana Mabel Serrani. Campinas: Editora da UNICAMP, 1988b. p. 293-307.

PÊCHEUX, M. [1983] 'Papel da memória'. In: ACHARD, P. et al. (org.), Papel da memória. Pontes, São Paulo, 1999. p. 49-57.

SAAL, F.; BRAUNSTEIN, N. El sujeto en el psicoanálisis, el materialismo histórico y la lingüística. In: BRAUNSTEIN, N. [1980] Psiquiatría, teoría del sujeto, psicoanálisis (hacia Lacan). Cd. de México: Siglo veintiuno Ed., 2008. p. 80-16o.

SANTOS, A. de F. T. Política educacional para a universidade microondas: gestão universitária, trabalho docente e qualidade da formação humana sob o efeito do "mercado edeucador". Revista Gestão Universitária na América Latina - GUAL, v. o3, p. 01-16, 2010.

SANTOS, M. [1996] Da totalidade ao lugar. São Paulo: Editora da Universidade de São Paulo, 2005 . 
SHAW, G. B. [1912] Pygmalion. In: SHAW, G. B. Four plays by George Bernard Shaw: Candida, Cesar and Cleopatra, Pygmalion, Heartbreak House. Introduction by Louis Kronenberger. New York: The Modern Library, 1953.

Recebido em 16/09/2018.

Aprovado em 22/11/2018. 